\title{
Dimentional accuracy of intraoral and laboratory scanners: A literature review
}

\author{
Iman Shafiei', Mehran Bahrami² and Saied Nokar ${ }^{3 *}$ \\ ${ }^{1}$ Prosthetic Department, School of Dentistry, Tehran University of Medical Sciences, Tehran, Iran \\ ${ }^{2}$ Assistant Professor, Dental Research Center, Department of Prosthodontics, School of Dentistry, Tehran \\ University of Medical Sciences, North Amirabad Ave, Tehran, Iran \\ ${ }^{3}$ Associate Professor, Department of Prosthodontics, Dental Research Center, Tehran University of Medical \\ Sciences, Tehran, Iran
}

\begin{abstract}
Restoration of dental implants remains one of the most challenging aspects of implant dentistry. Although it is not clear whether prosthetic misfit could affect osseointegration, mechanical complications of implant-supported prostheses can be avoided by achieving a good passive fit between the framework and the implants. Passive fit is a difficult concept to define. Obtaining absolute passive fit of the prosthetic framework on implants has been reported to be nearly impossible. Dimentional accuracy of intraoral and laboratory scanners play deniable role on producing desirable restorations. So, the aim of the current research was to determine dimentional accuracy of intraoral and laboratory scanners using the PubMed and Medline database English literature by the terms "Dimentional accuracy", "Intraoral", Laboratory scanners".
\end{abstract}

KEY WORDS: DIMENTIONAL ACCURACY, INTRAORAL SCANNERS, LABORATORY SCANNERS, DIGITAL IMPRESSION, TRUNESS, PRECISION, CAD CAM PROSTHODONTICS

\section{INTRODUCTION}

Technique of computer aided design and computer aided manufacturing (CAD/CAM) is used to produce ceramic restorations such as all-ceramic crowns and fixed dental prostheses since decades ago (Su et al. 2015). Numerous CAD/CAM systems are capable of designing and

\section{ARTICLE INFORMATION:}

*Corresponding Author: snir2500@yahoo.com Received 30 ${ }^{\text {th }}$ Sep, 2017

Accepted after revision $1^{\text {st }}$ Dec, 2017

BBRC Print ISSN: 0974-6455

Online ISSN: 2321-4007 CODEN: USA BBRCBA

Thomson Reuters ISI ESC and Crossref Indexed Journal

NAAS Journal Score 2017: 4.31 Cosmos IF: 4.006

- A Society of Science and Nature Publication, 2017. All rights reserved.

Online Contents Available at: http//www.bbrc.in/

DOI: $10.21786 / \mathrm{bbrc} / 10.4 / 26$ fabricating prostheses on plaster cast made from conventional silicone impressions (Mo“rmann, 2006). Nonstandard operation during impression taking and deformation of clinical material will affect the accuracy of plaster model, consequently affecting the accuracy of three-dimensionalmodels (3D) model data and prostheses quality (Stimmelmayr et al. 2012). So, it is desirable 
to develop a facility which can take digital impressions directly from oral cavity to eliminate error and also economize on impression materials used in conventional impression procedures. The primery digital intraoral impression system commercially available was CEREC 1 system (Rekow, 2006). Laboratory digitizing starts with a conventional impression that is poured, and the leads model is digitized, using one of numerous optical or mechanical systems (Beuer et al. 2004). Also, some systems offer the possibility to scan the impression directly without cast fabrication (Güth et al. 2013).

In addition, discomfort for the patient like sweating, gagging, pain and partially inconvenient taste is a known issue associated with conventional impression taking. In these situations, this instability and discomfort factor might be avoided by direct data capturing, which represents a logical direct access to dental CAD/ CAM (Steinhäuser-Andresen et al. 2011). To date few published literature exists on the performance of digital intraoral impression system, especially concerning the accuracy and precision of intraoral scanners. So, the aim of the current research was to determine dimentional accuracy of intraoral and laboratory scanners.

\section{MATERIAL AND METHODS}

The keywords used for the literature search for this review was peer-reviewed articles following key-words: Dimentional accuracy $\times$ Intraoral scanners and Laboratory scanners. Among them, the papers were fit the criteria selected and available full-text articles read. Related articles were also scrutinized. Hand search was also driven. The search was carried out using Biological Abstracts, Chemical Abstracts, and the data bank of the PubMed and Medline database updated to 2017. The references found in the search were then studied in detail.

\section{HISTORY OF DIGITAL SYSTEMS IN DENTISTRY}

To achieve a correct adaptation between the prosthesis and the implants, the first step is to obtain a highly accurate impression. Many clinical factors affect the accuracy of the impressions, such as tray type, impression technique, impression material used and its particular hydrophobic or hydrophilic characteristics, mixing methods and impression disinfection. Impressions can be made at either the implant level or the abutment level (Giménez et al. 2015). Computer-aided design/computer aided manufacturing (CAD/CAM) systems have evolved over the last two decades and have been used by dental health professionals for over twenty years (Duret et al. 1998). Francois Duret introduced CAD/CAM in restorative dentistry (Priest, 2005). One of the main lines of implementation was the intraoperative use for dental restoration using prefabricated ceramic monoblocks (Mörmann, 2004). Dental CAD/CAM's evolution over the past30 years has centered on the chairside market, beginning with CEREC ${ }^{\circledR}$ (Sirona). This is in part because the appeal of the CAD/CAM concept is that it offers dental professionals and their patients the convenience of same-day dentistry (Davidowitz and Kotick, 2011). A further development in CAD/CAM technology is the transition from closed file format to open access file systems, which opens up access to a much wider range of manufacturing technology such that the most appropriate manufacturing processes and associated materials can be selected (van Noort, 2012).

The CAD/CAM systems have been used mostly for the manufacturing of prosthetic fixed restorations, such as inlays, onlays, veneers and crowns. During the last decade technological developments in these systems have provided alternative restorations using different materials such as porcelain, composite resin and metallic blocks, which could not be prosecuted previously because of technical limitations. To date several optical impression systems have been developed with which direct impressions could be made in the oral cavity including Cerec AC (Sirona, Behnheim), Lava Chairside Oral Scanner (Lava COS, 3 M ESPE), E4D Dentist (D4D Technologies, LLC) and iTero (Cadent, Carlstadt) (Giménez et al. 2015). Despite numerous advantages introduced for dental implants, several challenges, since excellent accuracy is a prerequisite to achieve proper fit of the subsequent prosthesis (Giménez et al. 2014). There is scarce information on the accuracy of intraoral digital impression systems for dental implants including the implant-related factors and other clinical aspects such as the experience of the operator.

\section{APPLICATION OF SCANNERS IN DENTISTRY}

For the acquisition of digital images of teeth, different procedures have been described: digitization of plaster casts, digitization of impressions, and intraoral digital impressions (Morris et al. 2010). Digital work flow has been proposed to improve treatment planning, give higher efficiency, and allow new methods of production and new treatment concepts (Galovska et al. 2012). Data storage and reproducibility are facilitated, and treatment documentation and communication between professionals as well as between dentists and patients have become more convenient ( $\mathrm{Al}$ Mortadi et al. 2012). Currently, there are a major digital impression devices: iTero (Align Technologies, San Jose, Calif), Lava COS (3M ESPE, Seefeld, Germany), and Trios (3Shape, Copenhagen, Denmark) for image acquisition; and CEREC AC (Sirona, Bensheim, Germany) and E4D (D4D Technologies, Richardson, Tex) for digital imaging and in-office manufacturing (Flugge et al. 2013). All scanning devices 
need drying and powdering of intraoral surfaces (CEREC, E4D, Lava COS). Also, digital impressions are acquired without contact to the gingival tissues (Ender and Mehl, 2011). Direct acquisitions systems have been constantly improved because this are less invasive, quicker and more precise than the conventional methods. Besides the digital image can be easily store for a long time (Ramsey and Ritter, 2012).

\section{TYPES OF INDIRECT IMPRESSIONS}

\section{Lost-wax}

Lost-wax is the traditional technique for fabricating the metal substructure is the lost-wax technique and using various metal alloys for casting (Ucar et al. 2009). Conventionally, wax patterns were fabricated with wax and waxing instruments for example the popular PKT instruments. Wax is used to make the patterns because it can be conveniently manipulated, precisely shaped and can also be completely eliminated from the mold by heating. The fabrication of the wax pattern is the most critical and labor-intensive step in making the porcelain fused-metal crown (Vojdani et al. 2013). To fabricate a restoration prepared using the lost-wax technique, the dentist must first make an impression and the impression appointment may be uncomfortable for the patient because of the retraction procedure and need for anesthesia. Subsequently, time is required by the dental laboratory technician for careful pouring of the stone die or cast from the impression, preparation of the cast, then fabrication of the wax pattern, investing, and casting. Considering the lower unit cost of base metal alloys, a more economical dental laboratory technique would be helpful to replace the previously described technique for preparing cast restorations (Ucar et al. 2009).

Selective laser sintering (SLS) is a manufacturing technology recently introduced in dentistry. SLS, is one of the fast prototyping production techniques, uses a hightemperature laser to beam selectively substructure metal powder based on the CAD data with the fixed dental prostheses design. A thin layer of the beamed area becomes burnt and the fixed dental prostheses is completed by laminating these thin layers. The metal-ceramic crown is formerly one of the most commonly used fixed dental prostheses and the lower core is mostly produced by the lost wax technique and casting method. However, SLS system has several benefits such as material, time and expenses saving was well as the production is simpler compared to the existing methods (Akova et al. 2008).

\section{CEREC}

With CEREC 1 and CEREC 2, an opticalscan of the prepared tooth is made with a couple charged device (CCD) camera, and a 3-dimensional digital image is generated on the monitor. The restoration is then designed and milled. With the newer CEREC 3D, the operator records multiple images within seconds, enabling clinicians to prepare multiple teeth in the same quadrant and create a virtual cast for the entire quadrant. The restoration is then designed and transmitted to a remote milling unit for fabrication. While the system is milling the first restoration, the software can virtually seat the restoration back into the virtual cast to provide the adjacent contact while designing the next restoration (Estafan et al. 2003).

\section{DCS Precident}

The DCS Precident system is comprised of a Preciscan laser scanner and Precimill CAM multitool milling center. The DCS Dentform software automatically suggests connector sizes and pontic forms for bridges. It can scan 14 dies simultaneously and mill up to 30 framework units in 1 fully automated operation. Materials used with DCS include porcelain, glass ceramic, In- Ceram, dense zirconia, metals, and fiber- reinforced composites. This system is one of the few CAD/CAM systems that can mill titanium and fully dense sintered zirconia (Sjogren et al. 2004).

\section{Procera}

Procera/AllCeram was introduced in 1994 and according to company data, has produced 3 million units as of May 2004. Procera uses an innovative concept for generating its alumina and zirconia copings. First, a scanning stylus acquires 3D images of the master dies that are sent to the processing center via modem. The processing center then generates enlarged dies designed to compensate for the shrinkage of the ceramic material. Copings are manufactured by dry pressing high-purity alumina powder (>99.9\%) against the enlarged dies. These densely packed copings are then milled to the desired thickness. Subsequent sintering at $2,000^{\circ} \mathrm{C}$ imparts maximum density and strength to the milled copings. The complete procedure for Procera coping fabrication is very technique-sensitive because the degree of die enlargement must precisely match the shrinkage produced by sintering the alumina or zirconia (Posselt et al. 2003).

\section{Lava}

Lava introduced in 2002, Lava uses a laser optical system to digitize information from multiple abutment margins and the edentulous ridge. The Lava CAD software automatically finds the margin and suggests a pontic. The framework is designed to be $20 \%$ larger to compensate for sintering shrinkage. After the design is complete, a properly sized semisintered zirconia block is selected for milling. The block is bar coded to register the special design of the block. The computer- controlled 
precision milling unit can mill out 21 copings or bridge frameworks without supervision or manual intervention. Milled frameworks then undergo sintering to attain their final dimensions, density, and strength. The system also has 8 different shades to color the framework for maximum esthetics (Bindl et al. 2004).

\section{Everest}

Marketed in 2002, the Everest system consists of scan, engine, and therm components. In the scanning unit, a reflection-free gypsum cast is fixed to the turntable and scanned by a CCD camera in a 1:1 ratio with an accuracy of measurement of $20 \mu \mathrm{m}$. A digital 3D model is generated by computing 15 point photographs. The restoration is then designed on the virtual 3D model with Windows-based software. Its machining unit has 5-axis movement that is capable of producing detailed morphology and precise margins from a variety of materials including leucite-reinforced glass ceramics, partially and fully sintered zirconia, and titanium. Partially sintered zirconia frameworks require additional heat processing in its furnace (Blatz et al. 2003).

\section{Cercon}

The Cercon System is commonly referred to as a CAM system because it does not have a CAD component. In this system, a wax pattern (coping and pontic) with a minimum thickness of $0.4 \mathrm{~mm}$ is made. The system scans the wax pattern and mills a zirconia bridge coping from presintered zirconia blanks. The coping is then sintered in the Cercon heat furnace $\left(1,350^{\circ} \mathrm{C}\right)$ for 6 to 8 hours. A low-fusing, leucite-free Cercon Ceram $\mathrm{S}$ veneering porcelain is used to provide the esthetic contour. In an in vitro study the marginal adaptation for Cercon allceramic crowns and fixed partial dentures was reported as $31.3 \mu \mathrm{m}$ and $29.3 \mu \mathrm{m}$, respectively (Ariko et al. 2003).

\section{INTRAORAL AND LABORATORY SCANNERS}

Several intraoral scanners have been introduced in the recent decades, and an increasing number of dental clinics have decided to adopt these powerful devices for capturing digital impressions (Mangano et al. 2016). Capturing of digital impressions of the dental arches using this system can done by only a light beam, without the need of individual trays and materials (alginate, silicone, polyether) that are traditionally used to take impressions (Logozzo et al. 2014). Because of the unpleasant procedure, especially for those with a pronounced gag reflex conventional impressions are generally not appreciated by patients (Zimmermann et al. 2015). The possibility to effectively replace conventional impressions is the main advantage of intraoral digital impressions, which leads to decrease materials costs (Yuzbasioglu et al. 2014).
Immediate control of the quality of the impression, and the possibility of obtaining 3D which can be electronically sent to the laboratory is known as advantages for this system (Schepke et al. 2015).

Digital impression making has improved this process and the ability to evaluate the preparation in realrime. Having the capability of acquiring a scan of a prepared tooth and visualizing it on a computer monitor eliminates the issues associated with conventional impressions. The dentist is now able to see a magnified high-resolution image of exactly what is present in the oral cavity and not just a negative representation. This improved visualization enables the dentist to see and evaluate, in exquisite detail, the quality of the preparations, while the patient is still in the chair. Factors such as preparation taper, quality of margins, undercuts, inter-occlusal clearance, and path of draw can be colorcoded displayed and directly corrected if necessary, and a new digital impression can be made within seconds. All of the currently available conventional impression materials exhibit some degree of dimensional change that builds distortion and inaccuracy into the final restoration. Digital impressions can reduce the possibility of dimensional change (shrinkage) that is evident with all conventional impression materials. Voids, tears, and pulls that are routinely experienced with conventional materials are no longer an issue with digital scans (Gebhards et al. 2010).

Laboratory digitizing starts with a conventional impression that is poured, and the resulting model is digitized, by using one of several optical or mechanical systems (Beuer et al. 2008). As well, some systems offer the possibility to scan the impression directly without cast fabrication (Quaas et al. 2007). However, in either instance, the initial step of the highly precise digital workflow is an analogue impression. Conventional high precision impression materials, like hydrocolloid, polyether, polyvinyl or polysulfide in combination with stone casts, offer a well-known procedure to transfer the clinical situation into the laboratory. However, some drawbacks are related to the sensitive process steps of this technique (Haim et al. 2009).

The CAD-CAM system includes three parts, which correspond to the three basic steps of the process: (I) First, a device is used to input the existing dental shapes into the system. This device includes a laser source (diode) which, through the first endoscope, projects light on the desired picture area. A second endoscope, adjacent to the first, allows a camera to take pictures in the mouth. This camera is connected to a system that digitizes the information and correlates the different views (Duret et al. 1985). (II) The CAD system, including all necessary hardware and software, allows the operator to create an electronic model of the impression, display 
it on the screen, an d use it to design the prosthesis. The CAD system is linked to a proprietary articulator, called the Access Articulator, which provides the data relating to the dynamic movements of the jaw. (III) The CAM system, which includes a numerically controlled machine tool with four-axis capability. This machine will automatically mill the prosthesis from conventional or special materials (Belser et al. 1985).

\section{Comparison of the accuracy of direct and indirect}

To date numerous researches have been done on comparison of the accuracy of direct and indirect dental scanners. However, proces and cones reported for each system, here we highlighted the most significsnt findings of the previous reports. For the precision of direct digital impression, Guth et al. (2013) compared the 3D average and standard deviations of intraoral digital impression (Lava Chairside Oral Scanner) with those of extraoral desktop scanner (Lava Scan ST laboratory scanner) in an in-vitro study where a molar and premolar were scanned. It revealed the 3D standard deviations of $19 \mu \mathrm{m}$ for the intraoral digital scanner and $31 \mu \mathrm{m}$ for the extraoral scanner. Ender and Mehl (2011) compared the trueness and precision of digital impressions of the full arch with those of conventional impressions using a reference scanner on a in-vitro model, and the results showed that precision was $61.3 \pm 17.9 \mu \mathrm{m}$ for conventional impression, $30.9 \pm 7.1 \mu \mathrm{m}$ for digital impression with the Cerec Bluecam and $60.1 \pm 31.3 \mu \mathrm{m}$ for digital impression with Lava C.O.S.

Guth et al. (2013) found that digital impressions made using Lava C.O.S. were more accurate than a laboratory scan of a conventional impression and conversion to a digital file. Mangano et al. (2016) in research on trueness and precision of four intraoral scanners in oral implantology revealed in the partially edentulous maxilla, CS 3500 had the best general trueness $(47.8 \mu \mathrm{m})$ and precision $(40.8 \mu \mathrm{m})$, followed by Trios (trueness $71.2 \mu \mathrm{m}$, precision $51.0 \mu \mathrm{m}$ ), Zfx Intrascan (trueness $117.0 \mu \mathrm{m}$, precision 126.2 $\mu \mathrm{m}$ ), and Planscan (trueness $233.4 \mu \mathrm{m}$, precision219.8 $\mu \mathrm{m})$. With regard to general trueness, Trios was significantly better than Planscan, CS 3500 was significantly better than Zfx Intrascan and Planscan and Zfx Intrascan was significantly better than Planscan; with regard to general precision, Trios was significantly better than Zfx Intrascan and Planscan, CS 3500 was significantly better than Zfx Intrascan and Planscan and Zfx Intrascan was significantly better than Planscan. In the totally edentulous maxilla, CS 3500 had the best performance in terms of general trueness $(63.2 \mu \mathrm{m})$ and precision $(55.2 \mu \mathrm{m})$, followed by Trios (trueness71.6 $\mu \mathrm{m}$, precision $67.0 \mu \mathrm{m}$ ), Zfx Intrascan (trueness $103.0 \mu \mathrm{m}$, precision $112.4 \mu \mathrm{m}$ ), and Planscan (trueness $253.4 \mu \mathrm{m}$, precision $204.2 \mu \mathrm{m})$. With regard to general trueness,
Trios was significantly better than Planscan, CS 3500 was significantly better than Zfx Intrascan and Planscan and Zfx Intrascan was significantly better than Planscan with regard to general precision, Trios was significantly better than Zfx Intrascan and Planscan, CS 3500 was significantly better than Zfx Intrascan and Planscan and Zfx Intrascan was significantly better than Planscan. Local trueness values confirmed these results (Mangano et al. 2016).

On Precision of intraoral digital dental impressions with iTero and extraoral digitization with the iTero and a model scanner Flugge et al. (2013) reported scanning with the iTero is less accurate than scanning with the D250. Intraoral scanning with the iTero is less accurate than model scanning with the iTero, suggesting that the intraoral conditions (saliva, limited spacing) contribute to the inaccuracy of a scan. For treatment planning and manufacturing of tooth-supported appliances, virtual models created with the iTero can be used. An extended scanning protocol could improve the scanning results in some regions. In a study on accuracy $3 \mathrm{M}$ Lava C.0.S., 3Shape D900, Cadent iTero, CEREC Bluecam, and E4D Dentistdigital impression systems revealed digital impressions from the Cadent iTero system were the most accurate (Ali, 2015).

Recently, on comparison of repeatability between intraoral digital scanner and extraoral digital scanner, Su et al. (2015) revealed precision decreases with the increased scanning scope. Precision was clinically acceptable when scanning scope was less than half arch. Precision of extraoral scanning was acceptable in scanning any scope of arch region. Güth et al. (2013) revealed the direct digitalisation with Lava C.O.S. showed statistically significantly higher accuracy compared to the conventional procedure of impression taking and indirect digitalisation.

\section{REFERENCES}

Akova T, Ucar Y, Tukay A, Balkaya MC, Brantley WA. 2008 Comparison of the bond strength of laser-sintered and cast base metal dental alloys to porcelain. Dent Mater 24: 1400-4.

Al Mortadi N, Eggbeer D, Lewis J, Williams RJ. 2012 CAD/ CAM/AM applications in the manufacture of dental appliances. Am J Orthod Dentofacial Orthop 2012;142:727-33.

Ali A0 (2015) Accuracy of Digital Impressions Achieved from Five Different Digital Impression Systems. Dentistry 5: 300.

Ariko K. 2003 Evaluation of the marginal fitness of tetragonal zirconia polycrystal all-ceramic restorations. Kokubyo Gakkai Zasshi. 2003;70:114-123. Japanese.

Belser UC, MacEntee M.I, Richter WA. 1985 Fit of three porcelain-fused-to-metal marginal designs in vivo: and a scanning electron microscope study. J Prosthet Dent (53):24-34 
Beuer F, Schweiger J, Edelhoff D (2008) Digital dentistry: an overview of recent developments for CAD/CAM generated restorations. Br Dent J 204:505-511

Beuer F, Schweiger J, Edelhoff D (2008) Digital dentistry: an overview of recent developments for CAD/CAM generated restorations. Br Dent J 204:505-511

Bindl A, Mormann WH. 2004 Survival rate of mono-ceramic and ceramic-core $\mathrm{CAD} / \mathrm{CAM}$ generated anterior crowns over 2-5 years. Eur J Oral Sci.2004;112:197-204.

Blatz MB, Sadan A, Blatz U. 2003 The effect of silica coating on the resin bond to the intaglio surface of Procera AllCeram restorations. Quintessence Int. 2003;34:542-547.

Davidowitz, G. \&t Kotick, P.G. (2011) The use of CAD/CAM in Dentistry. Dental Clinics of North America, 55(3), 559-570.

Duret F, Blouin JL, Duret B. CAD-CAM in dentistry. J Am Dent Assoc. 1988;117:715-20.

Duret, F.: Duret, B.; el Blouin, J.L. 1985 Bases fondamentales dans la conception et fabrication assistées par ordinateur des prostheses dentaires. QOS 39:197-215

Ender A, Mehl A. 2011 Full arch scans: conventional versus digital impressions-an in-vitro study. Int J Comput Dent 14:11-21.

Estafan D, Dussetschleger F, Agosta C 2003 Scanning electron microscope evaluation of CEREC II and CEREC III inlays. Gen Dent. 51:450-454.

Flugge TV, Schlager S, Nelson K, Nahles S, Metzger MC. 2013 Precision of intraoral digital dental impressions with iTero and extraoral digitization with the iTero and a model scanner. Am J Orthod Dentofacial Orthop 144:471-8

Galovska M, Petz M, Tutsch R. 2012 Unsicherheit bei der datenfusion dimensioneller messungen. tm-Technisches Messen 79: 238-45.

Gebhards, A., Schmidt, F.M., \&t Hotter, J.S. (2010) Additive Manufacturing by selective laser melting the realizer desktop machine and its application for the dental industry. Physics Procedia, 5, 543-549.

Giménez B, Pradies G, Martínez-Rus F, Özcan M. 2015 Accuracy of two digital implant impression systems based on confocal microscopy with variations in customized software and clinical parameters. Int J Oral Maxillofac Implants 30:56-64.

Giménez Be, Özcan M, MR Francisco, Pradies G. 2014 Accuracy of a digital impression system based on parallel confocal laser technology for implants with consideration of operator experience and implant angulation and depth. Int J Oral Maxillofac Implants 29:853-862.

Gu th J-F, Keul C, Stimmelmayr M, Beuer F, Edelhoff D. 2013 Accuracy of digital models obtained by direct and indirect data capturing. Clin Oral Investig 17:1201-8.

Güth FJ, Keul C, Stimmelmayr M, Beuer F, Edelhoff D. 2013 Accuracy of digital models obtained by direct and indirect data capturing. Clin Oral Invest 17:1201-1208.

Haim M, Luthardt RG, Rudolph H, Koch R, Walter MH, Quaas S(2009) Randomized controlled clinical study on the accuracy of two-stage putty-and-wash impression materials. Int J Prosthodont 22:296-302.

Logozzo S, Zanetti EM, Franceschini G, Kilpela A, Makynen A. 2014 Recent advances in dental opticsĐ Part I: 3D intraoral scanners for restorative dentistry. Optics Lasers Eng 54 (3): 203-221.

Mangano FG, Veronesi G, Hauschild U, Mijiritsky E, Mangano C (2016) Trueness and Precision of Four Intraoral Scanners in Oral Implantology: A Comparative in Vitro Study. PLoS ONE 11(9): e0163107.

Mo"rmann WH. The evolution of the CEREC system. J Am Dent Assoc $2006 ; 137$ (September (Suppl)):7S-13S.

Mörmann WH. 2004 The origin of the Cerec method: a personal review of the first 5 years. Int J Comput Dent. 7:11-24.

Morris JB. 2010 CAD/CAM options in dental implant treatment planning. J Calif Dent Assoc :333-6.

Posselt A, Kerschbaum T. 2003 Longevity of 2,328 chairside Cerec inlays and onlays. Intl J Comput Dent. 6:231-248.

Priest G. 2005 Virtual-designed and computer-milled implant abutments. J Oral Maxillofac Surg. 63:22-32.

Quaas S, Rudolph H, Luthardt RG (2007) Direct mechanical data acquisition of dental impressions for the manufacturing of CAD/ CAM restorations. J Dent 35:903-908

Ramsey CD, Ritter RG. 2012 Utilization of digital technologies for fabrication of definitive implant-supported restorations. J Esthet Restor Dent. 24(5):299-308.

Rekow ED. 2006 Dental CAD/CAM systems: a 20-year success story. J Am Dent Assoc 137(Suppl):5S-6S

Schepke U, Meijer HJ, Kerdijk W, Cune MS. 2015 Digital versus analog complete-arch impressions for single- unit premolar implant crowns: Operating time and patient preference. J Prosthet Dent 114(3): 403+406 e1.

Sjogren G, Molin M, van Kijken JW. 2004 A 10-year prospective evaluation of CAD/CAM-manufactured (Cerec) ceramic inlays cemented with a chemically cured or dual-cured resin composite. Int J Prosthodont. 17:241-246.

Steinhäuser-Andresen S, Detterbeck A, Funk C, Krumm M, Kasperl S, Holst A, Hirschfelder U (2011) Pilot study on accuracy and dimensional stability of impression materials using industrial CT technology. J Orofac Orthop 72:111-124

Stimmelmayr M, Gu“ th JF, Erdelt K, Edelhoff D, Beuer F. 2012 Digital evaluation of the reproducibility of implant scanbody fit-an in vitro study. Clin Oral Investig 16:851-6.

Su T-, Sun J. 2015 Comparison of repeatability between intraoral digital scanner and extraoral digital scanner: An invitro study. J Prosthodont Res (2015), http://dx.doi. org/10.1016/j.jpor.2015.06.002

Ucar Y, Akova T, Akyil MS, Brantley WA. 2009 Internal fit evaluation of crowns prepared using a new dental crown fabrication technique: Laser-sintered Co-Cr crowns. J Prosthet Dent 2009;102:253-259

Van Noort, R. (2012) The future of dental devices is digital Dental Materials, 28(1), 3-12. 
Vojdani M, Torabi K, Farjood E, Khaledi AAR. 2013 Comparison the marginal and internal fit of metal copings cast from wax patterns fabricated by CAD/CAM and conventional wax up techniques. J Dent Shiraz Univ Med Sci, Sept. 14(3): 118-129.

Yuzbasioglu E, Kurt H, Turunc R, Bilir H. 2014 Comparison of digital and conventional impression techniques: evaluation of patients' perception, treatment comfort, effectiveness and clinical outcomes. BMC Oral Health, 14 (10): 7 pages.

Zimmermann M, Mehl A, Mormann WH, Reich S. 2015 Intraoral scanning systemsĐa current overview. Int J Comput Dent 18 (2): 101-129. 